\title{
Safety and efficacy of elbasvir/grazoprevir for the treatment of chronic hepatitis C: current evidence
}

This article was published in the following Dove Press journal:

Drug Design, Development and Therapy

\section{Kenichi Morikawa \\ Akihisa Nakamura \\ Tomoe Shimazaki \\ Naoya Sakamoto}

Department of Gastroenterology and Hepatology, Hokkaido University Faculty of Medicine and Graduate School of Medicine, Sapporo, Japan
Correspondence: Kenichi Morikawa Department of Gastroenterology and Hepatology, Hokkaido University Faculty of Medicine and Graduate School of Medicine, Kita I5, Nishi 7, Kita-ku, Sapporo, Hokkaido 060-8638, Japan $\mathrm{Tel}+8$ I II 70677 I5

Fax $+8 \mid$ II 7067867

Email kenichi.morikawa@med.hokudai. ac.jp

\begin{abstract}
Treatments for hepatitis $\mathrm{C}$ virus (HCV) have advanced greatly, becoming more efficacious with fewer adverse events, due to the availability of direct-acting antiviral agents, which target specific steps in the HCV life cycle. Recently, a combination regimen consisting of the HCV nonstructural protein 5A inhibitor elbasvir (EBR) and the HCV NS3/4A protease inhibitor grazoprevir (GZR) was approved for the treatment of patients with chronic HCV and genotypes (Gts) 1 and 4 in various countries. In Phase III trials, the combination of EBR/GZR (fixed-dose combination table or single agent) for 12 or 16 weeks of treatment with or without ribavirin resulted in a high sustained virological response at 12 weeks in treatment-naïve and treatment-experienced patients with HCV Gt 1a, 1b, 4, or 6, including special populations, such as individuals with advanced chronic kidney disease, HCV-HIV coinfection, and compensated cirrhosis. In this review, we focus on the mode of action, pharmacokinetics, clinical applications, efficacy, and safety profile of EBR/GZR, including special populations who have been considered refractory from the extensive evidence of clinical trials.
\end{abstract}

Keywords: HCV, DAAs, compensated LC, HCV/HIV

\section{Introduction}

Chronic hepatitis $\mathrm{C}$ virus (HCV) occurs in association with chronic inflammatory cell infiltration and hepatocellular necrosis because of HCV infection of the liver. Liver cirrhosis and the progression of hepatic fibrosis are critical stages of HCV-related liver disease, and can develop into hepatocellular carcinoma (HCC) in a multicentric manner. Therefore, the primary therapeutic goal of eradicating HCV by treatment with an antiviral drug is to terminate its progression to liver cirrhosis and HCC. ${ }^{1,2}$ Currently, the estimated number of patients with $\mathrm{HCV}$ is 71 million globally. ${ }^{3} \mathrm{HCV}$ is classified into six major genotypes (Gts), with Gt 1 being the most prevalent globally $(49.1 \%)$, followed by Gt $3(17.9 \%), 4(16.8 \%), 2(11.0 \%)$, and 5 or $6(<5 \%) .{ }^{4}$ Antiviral treatment for $\mathrm{HCV}$ infection has significantly improved since the advent of direct-acting antiviral (DAA) agents, such as boceprevir and telaprevir. First-generation DAAs with concomitant use of Pegylated interferon (IFN) and ribavirin (RBV) is associated with a high rate of adverse events (AEs). However, the combined use of second-generation DAAs without IFN, such as IFN-free regimens, improves treatment efficacy and decreases the incidence of AEs, yet a number of issues remain. As HCV patients get older, it becomes necessary to administer safer drugs. In addition, there are very limited treatment options for patients with chronic kidney disease (CKD), patients coinfected with HCV and HIV, patients with resistance-associated substitutions (RASs) as a result of prior treatment including DAAs, and patients with coadministered drugs due to complicated diseases. As such, novel agents with enhanced efficacy, tolerability, and convenience are required for unmet medical needs. 
A

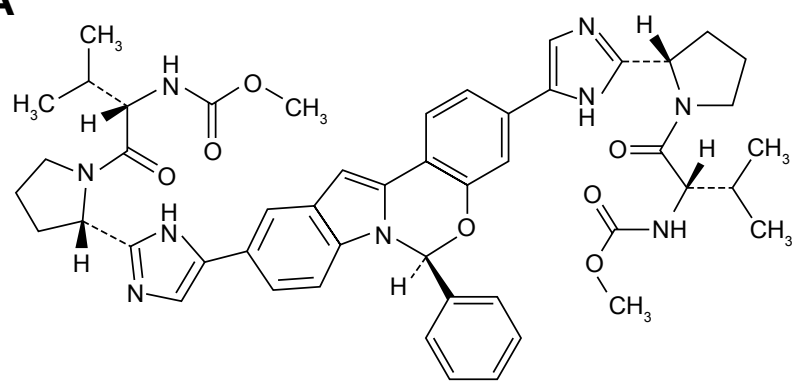

Elbasvir: $\mathrm{C}_{49} \mathrm{H}_{55} \mathrm{~N}_{9} \mathrm{O}_{7}$; molecular weight of $\mathbf{8 8 2 . 0 2}$

B

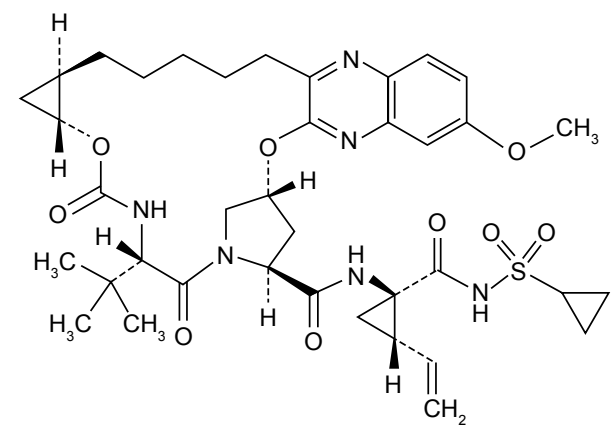

Grazoprevir: $\mathrm{C}_{38} \mathrm{H}_{50} \mathrm{~N}_{6} \mathrm{O}_{7}$; molecular weight of 776.90

Figure I Chemical structural formulae of elbasvir (A) and grazoprevir (B).

Recently, combination treatment with both the HCV nonstructural (NS) protein $5 \mathrm{~A}$ inhibitor elbasvir (EBR; Figure $1 \mathrm{~A})^{5}$ and the HCV NS3/4A protease inhibitor grazoprevir (GZR; Figure 1B) ${ }^{6}$ was approved in many countries for the treatment of patients with chronic HCV and Gt 1 and 4. This review covers the mode of action, pharmacokinetics, clinical applications, efficacy, and safety profile of EBR/ GZR, including special populations, from evidence to date.

\section{Properties of elbasvir/grazoprevir}

EBR inhibits HCV NS5A, which is necessary for assembly of the viral replication complex, RNA synthesis, and virion assembly (Figure 2). ${ }^{7-10}$ EBR has median effective concentration $\left(\mathrm{EC}_{50}\right)$ values against chimeric replicons containing NS5A from clinical isolates of Gt 1a, 1b, 2a, 2b, 3a, 4a, 5a, and 6 of $4,3,3,3,400,140,0.3,1$, and $9 \mathrm{pM}$, respectively (Table 1). ${ }^{11}$ GZR inhibits HCV NS3/4A protease, which has serine protease and NTPase/RNA helicase activities and is essential for viral polyprotein processing, RNA replication, and assembly (Figure 2). ${ }^{12-14}$ GZR has median $\mathrm{EC}_{50}$ values against chimeric replicons containing NS3/4A from clinical isolates of Gt 1a, 1b, 2a, 2b, 3a, 4a, 5a, and 6 of 400, 500, $2,300,3,700,35,000,300,6,600$, and $200 \mathrm{pM}$, respectively (Table 2). ${ }^{11}$ In the HCV-replicon assay, the antiviral activity of EBR is reduced one- to 929 -fold by single NS5A substitutions (known as RASs) at amino-acid positions M28T/V/A, $\mathrm{Q} 30 \mathrm{D} / \mathrm{H} / \mathrm{E} / \mathrm{R}, \mathrm{L} 31 \mathrm{M} / \mathrm{V} / \mathrm{F}, \mathrm{H} 58 \mathrm{D}$, and $\mathrm{Y} 93 \mathrm{H} / \mathrm{N} / \mathrm{C}$ in the $\mathrm{HCV}$ Gt 1a replicon, one- to 17-fold by single NS5A substitutions at amino-acid positions $\mathrm{L} 28 \mathrm{M}, \mathrm{L} 31 \mathrm{M} / \mathrm{F} / \mathrm{V}, \mathrm{Y} 93 \mathrm{H}$, and V121I in the HCV Gt $1 \mathrm{~b}$ replicon, and one- to 7.5-fold by single NS5A substitutions at amino-acid positions L30F/P/S, M31V, N69K, and $\mathrm{Y} 93 \mathrm{H}$ in the HCV Gt four replicon (Table 3). ${ }^{11,15,16}$ In the same way, the antiviral activity of GZR is reduced 1.1- to 114-fold by single NS3 substitutions at amino-acid positions V36A, T54S, Y56H, Q80K, R155K, A156S, and D168A/Y/T in the HCV Gt 1a replicon, 0.6- to 262-fold by single NS3 substitutions at amino-acid positions Q41R, F43S, R155K, A156T, and D168Y in the HCV genotype 1b replicon, and 47.1- to 137.1-fold by double-NS3 substitutions at amino-acid positions G162R with D168A, and G162R with D168V in the HCV Gt 4 replicon (Table 4). ${ }^{11,15,16}$

Concentrations of $50 \mathrm{mg}$ EBR and $100 \mathrm{mg}$ GZR can be administered as a fixed-dose combination of a single oncedaily tablet. Peak plasma concentrations of EBR and GZR are reached at a median of 3 and 2 hours, respectively, after oral administration, ${ }^{5,6}$ and steady-state pharmacokinetics reached within 6 days. EBR/GZR can be administered without regard to food, as changes in drug exposure are not clinically relevant after a high-calorie, high-fat meal in healthy subjects. EBR and GZR are highly bound to $99.9 \%$ and $98.8 \%$ of plasma proteins, respectively. Both EBR and GZR are mainly metabolized by CYP3A, after which both agents are predominantly excreted in feces. The approximate half-lives of EBR and GZR are 24 and 31 hours, respectively. EBR/GZR dose does not need to be adjusted in patients with renal impairment, including those on hemodialysis. Both EBR and GZR are CYP3A substrates, and thus coadministration of EBR/GZR with strong CYP3A inducers is contraindicated. GZR is a substrate of organic anion-transporting polypeptides 1B1/3 (OATP1B1/3), and thus coadministration of EBR/GZR with OATP1B1/3 inhibitors is also contraindicated. Plasma concentrations of tacrolimus and statins have the potential to increase after combination use of EBR/GZR, so clinical monitoring after administration of those drugs is recommended. However, EBR/GZR does not have any specific prohibition and caution as concomitant medications relative to the same class of drugs. It is not necessary either to take special consideration in combination use of EBR/GZR with calcium blockers, proton-pump inhibitors, or oral contraceptive drugs.

\section{Clinical outcomes of elbasvir- grazoprevir}

In the C-EDGE TN trial, in treatment-naïve (TN) patients infected with Gt 1a or $1 b$ and receiving EBR/GZR for 12 weeks 


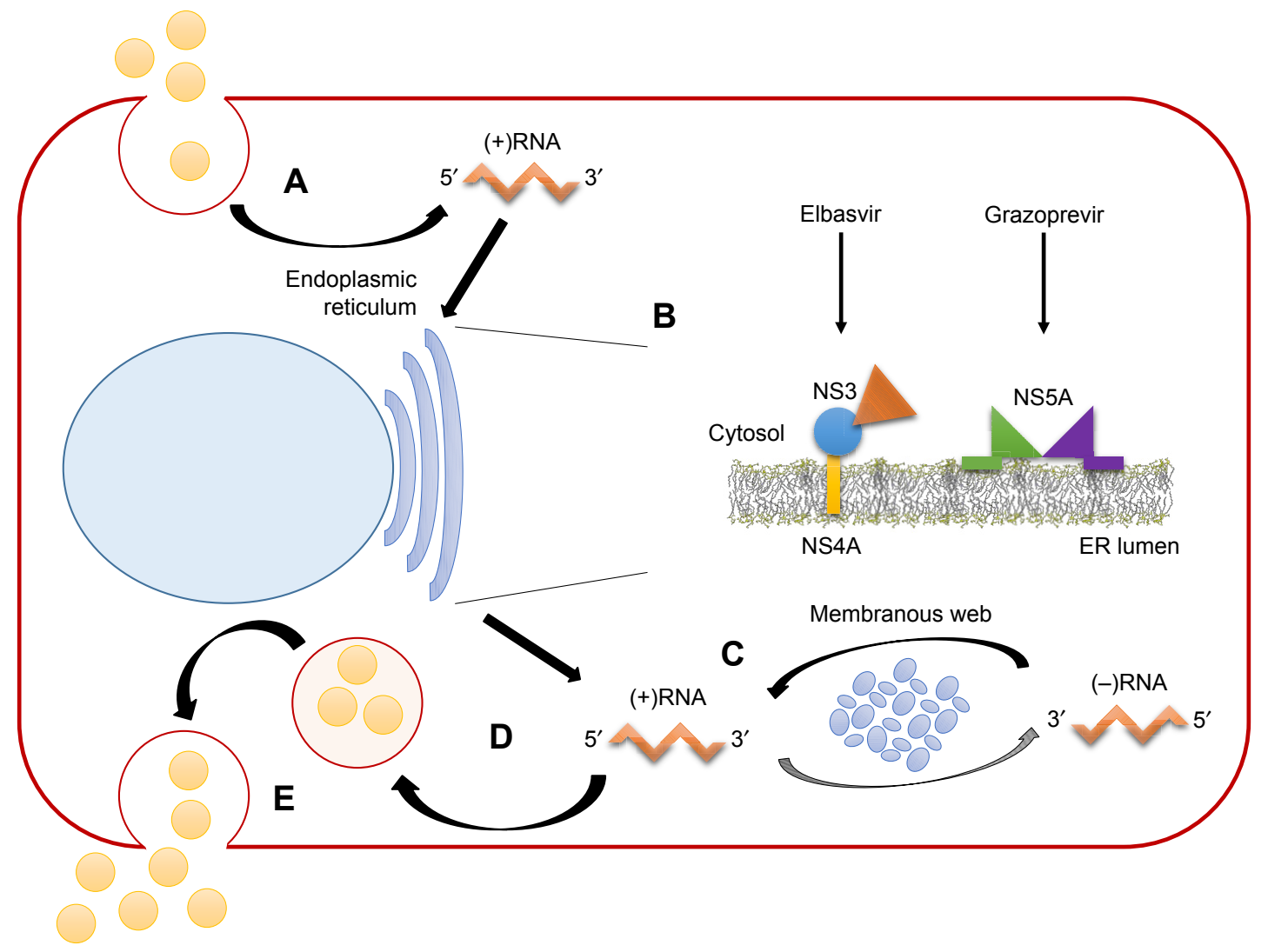

Figure 2 Life cycle of hepatitis $\mathrm{C}$ virus (HCV) and targeting points of elbasvir and grazoprevir.

Notes: Major steps of the HCV life cycle are summarized: virus entry and uncoating of viral genome (A); translation and polyprotein processing (B); RNA replication (C); packaging and assembly (D); and virion release (E). Upon cleavage of the polyprotein, nonstructural HCV proteins form the replication complex in association with cellular factors, which leads to the formation of double-membrane vesicles, also called the membranous web, where replication takes place. Grazoprevir targets HCV NS3/4A protease, which has serine protease and NTPase/RNA helicase activities and is essential for viral polyprotein processing, RNA replication, and assembly. Elbasvir targets HCV NS5A, which is necessary for assembly of the viral replication complex, RNA synthesis, and virion assembly. Adapted by permission from Springer Nature. Nature, Nat Rev Microbiol. Replication of hepatitis C virus. Moradpour D, Penin F, Rice CM. Copyright 2007;5(6):453-463.'2

without RBV, sustained virological response at 12 weeks (SVR12) was $92 \%$ in patients infected with Gt 1a and $99 \%$ in those infected with Gt $1 \mathrm{~b}$ (Table 5). ${ }^{17}$ The presence of compensated cirrhosis in $23 \%$ of patients had no effect on SVR12.

Table I Antiviral activity of elbasvir in HCV replicons of genotypes I-6

\begin{tabular}{|c|c|c|}
\hline Genotype (Gt) of HCV replicon ${ }^{a}$ & $E C_{50}(n M)$ & $E C_{90}(n M)$ \\
\hline Gt la_H77_NC004IO2 & $0.004 \pm 0.002$ & $0.006 \pm 0.002$ \\
\hline Gt Ib_conI_AJ238799 & $0.003 \pm 0.001$ & $0.006 \pm 0.004$ \\
\hline Gt 2a_JFHI_AB047639 & $0.003 \pm 0.001$ & $0.019 \pm 0.01$ \\
\hline Gt 2b_AB030907/JFHI ${ }^{b}$ & $3.4 \pm 2.6$ & $\mathrm{II} \pm 4.8$ \\
\hline Gt 3a_S52_GU8I4263 & $0.14 \pm 0.09$ & $0.49 \pm 0.19$ \\
\hline Gt 4a_ED43_GU8I4265 & $0.0003 \pm 0.0001$ & $0.0005 \pm 0.0001$ \\
\hline Gt 5a_SAI3_AF064490/JFHI ${ }^{b}$ & $0.00 I \pm 0.00 \mathrm{I}$ & $0.002 \pm 0.002$ \\
\hline Gt 6_DQ278892/JFHIb & $0.009 \pm 0.006$ & $0.017 \pm 0.009$ \\
\hline
\end{tabular}

Notes: ${ }^{a}$ Names and numbers are strain designations and GenBank accession numbers; 'JFHI-based chimeric replicon harboring NS5A sequences of Gt $2 \mathrm{~b}, 5 \mathrm{a}$, and 6 were used. Values are mean $\pm S D(n \geq 3)$. Adapted with permission from Lahser FC, Bystol K, Curry S, et al. The combination of grazoprevir, a hepatitis $C$ virus (HCV) NS3/4A protease inhibitor, and elbasvir, an HCV NS5A inhibitor, demonstrates a high genetic barrier to resistance in HCV genotype Ia replicons. Antimicrob Agents Chemother. 2016;60(5):2954-2964."

Abbreviations: $\mathrm{EC}$, effective concentration; $\mathrm{HCV}$, hepatitis $\mathrm{C}$ virus.
In the open-label C-EDGE COINFECTION trial, TN patients coinfected with HIV with or without compensated cirrhosis were treated with EBR/GZR for 12 weeks. SVR12 rates were 97\% in patients infected with Gt 1a and $95 \%$ in those infected

Table 2 Antiviral activity of grazoprevir in HCV replicons of genotypes $1-6$

\begin{tabular}{lll}
\hline${\text { Genotype (Gt) of HCV } \text { replicon }^{\mathrm{a}}}$ & $\mathrm{EC}_{50}(\mathrm{nM})$ & $\mathrm{EC}_{90}(\mathrm{nM})$ \\
\hline Gt Ia_H77_NC004I02 & $0.4 \pm 0.2$ & $0.9 \pm 0.5$ \\
Gt Ib_conI_AJ238799 & $0.5 \pm 0.3$ & $\mathrm{I} .1 \pm 0.6$ \\
Gt 2a_JFHI_AB047639 & $2.3 \pm 1.2$ & $7.1 \pm 3.1$ \\
Gt 2b_AY232740/JFHI & \\
Gt 3a_S52_GU8I4263 & $3.7 \pm 1 . I$ & $7.8 \pm 2.1$ \\
Gt 4a_ED43_GU8I4265 & $35 \pm I 5$ & $153 \pm 35$ \\
Gt 5a_SAI3_AF064490/JFHI ${ }^{b}$ & $0.3 \pm 0.2$ & $0.8 \pm 0.4$ \\
Gt 6_DQ278892/JFHI ${ }^{b}$ & $6.6 \pm 0.6$ & $12.8 \pm 2.2$ \\
\hline
\end{tabular}

Notes: ${ }^{a}$ Names and numbers are strain designations and GenBank accession numbers; 'JFHI-based chimeric replicon harboring NS3-4A sequences of Gt 2b, 5a, and 6 were used. Values are mean $\pm S D(n \geq 3)$. Adapted with permission from Lahser FC, Bystol K, Curry S, et al. The combination of grazoprevir, a hepatitis $C$ virus (HCV) NS3/4A protease inhibitor, and elbasvir, an HCV NS5A inhibitor, demonstrates a high genetic barrier to resistance in $\mathrm{HCV}$ genotype la replicons. Antimicrob Agents Chemother. 2016;60(5):2954-2964."

Abbreviations: $\mathrm{EC}$, effective concentration; $\mathrm{HCV}$, hepatitis $\mathrm{C}$ virus. 
Table 3 Inhibitory effects of elbasvir against NS5A-variant replicons

\begin{tabular}{|c|c|}
\hline HCV replicon & $\begin{array}{l}\text { Fold shift } \\
\text { relative to } \mathbf{W T}^{\mathrm{a}}\end{array}$ \\
\hline la H77 (WT) & 1 \\
\hline Ia M28T & 15 \\
\hline Ia M28V & 1 \\
\hline Ia M28A & 61 \\
\hline Ia Q30D & 925 \\
\hline Ia Q30H & 6 \\
\hline Ia Q30E & 56 \\
\hline Ia Q30R & 16 \\
\hline Ia L3IM & 10 \\
\hline Ia L3IF & 96 \\
\hline Ia L3IV & 61 \\
\hline Ia H58D & 6 \\
\hline Ia Y93H & 220 \\
\hline Ia Y93N & 929 \\
\hline Ia Y93C & 11 \\
\hline Ib con I (WT) & 1 \\
\hline Ib L28M & 2 \\
\hline Ib L3IM & 1 \\
\hline Ib L3IF & 15 \\
\hline Ib L3IV & 4 \\
\hline Ib Y93H & 17 \\
\hline Ib VI2II & 0.2 \\
\hline 4a ED43 (WT) ${ }^{\mathrm{b}}$ & 1 \\
\hline 4a L30Fb & 15 \\
\hline 4a L30Pb & 1 \\
\hline 4a L30Sb & 4 \\
\hline 4a M3IVb & 2.5 \\
\hline 4a N69K & 1.5 \\
\hline $\mathrm{Y} 93 \mathrm{H}^{\mathrm{b}}$ & 7.5 \\
\hline
\end{tabular}

Notes: ${ }^{\mathrm{a}}$ The fold shift calculated using $\mathrm{EC}_{50}$ concentration; ${ }^{\mathrm{b}}$ chimeric replicons bearing resistant-associated substitutions generated in a Gt 2a (JFHI) backbone. Modified from Lahser et al," Asante-Appiah et al, ${ }^{15}$ and Liu et al. ${ }^{16}$

Abbreviations: EC, effective concentration; $\mathrm{HCV}$, hepatitis $\mathrm{C}$ virus; $\mathrm{Gt}$, genotype; WT, wild type.

with Gt 1b. ${ }^{18}$ In DAA-naïve HCV Gt 1a-infected patients who received a 12-week regimen of EBR/GZR, the presence of baseline NS5A polymorphisms at amino-acid positions M28, Q30, L31, and Y93 was associated with reduced efficacy.

Patients with NS5A polymorphisms at amino-acid positions Q30H/L/R or L31M had particularly low SVR12 rates $(<50 \%) .{ }^{19}$ In HCV Gt 1 b-infected patients who received a 12-week regimen of EBR/GZR, the presence of baseline NS5A polymorphisms was associated with slightly reduced SVR12 rates. ${ }^{19,20}$ Moreover, in HCV Gt 4-infected patients who received a 12-week regimen of EBR/GZR, the presence of baseline NS5A polymorphisms had little influence on SVR12 rates. ${ }^{19}$ Despite the fact that baseline NS3 RASs were commonly observed, a 12-week regimen of EBR/GZR demonstrated high SVR12 rates among patients infected with Gt 1a, 1b, or 4. ${ }^{17,19-24}$ In treatment-experienced (TE) patients in the C-EDGE TE Phase III trial, including 34\% of
Table 4 Inhibitory effects of grazoprevir against NS3A-variant replicons

\begin{tabular}{|c|c|}
\hline HCV replicon & $\begin{array}{l}\text { Fold shift relative } \\
\text { to } \mathrm{WT}^{\mathrm{a}}\end{array}$ \\
\hline Ia H77 (WT) & 1 \\
\hline Ia V36A & 1.2 \\
\hline Ia T54S & 1.1 \\
\hline Ia Y56H & 46 \\
\hline Ia Q80K & I.I \\
\hline Ia RI55K & 3 \\
\hline Ia AI56S & 2.5 \\
\hline Ia DI68A & 114 \\
\hline Ia DI68Y & 27 \\
\hline Ia VI70T & 2 \\
\hline Ib conI (WT) & 1 \\
\hline Ib Q4IR & 3.6 \\
\hline Ib F43S & 2.6 \\
\hline Ib RI55K & 0.6 \\
\hline Ib AI56T & 262 \\
\hline Ib DI68Y & 8 \\
\hline 4a ED43 (WT) ${ }^{b}$ & I \\
\hline $4 \mathrm{a} G 162 \mathrm{R}^{\mathrm{b}}$ & I \\
\hline 4a GI62R DI68A & 137.1 \\
\hline 4a GI62R DI68Vb & 47.1 \\
\hline
\end{tabular}

Notes: ${ }^{\mathrm{a}}$ Fold shift calculated using $\mathrm{EC}_{90}$ concentration in $\mathrm{Gt}$ la and $\mathrm{EC}_{50}$ concentration in $\mathrm{Gt} \mathrm{Ib}$ and 4a; ${ }^{b}$ chimeric replicons bearing resistant-associated substitutions generated in a Gt 2a (JFHI) backbone. Modified from Lahser et al," Asante-Appiah et al, ${ }^{15}$ and Liu et al. ${ }^{16}$

Abbreviations: $\mathrm{EC}$, effective concentration; $\mathrm{HCV}$, hepatitis $\mathrm{C}$ virus; $\mathrm{Gt}$, genotype; WT, wild type.

patients with compensated cirrhosis, SVR12 rates in patients infected with Gt $1 \mathrm{a}$ and $1 \mathrm{~b}$ were $92 \%$ and $100 \%$, respectively, after 12 weeks of EBR/GZR without RBV, 93\% and 97\%, respectively, after 12 weeks with RBV, 94\% and 98\%, respectively, after 16 weeks without $\mathrm{RBV}$, and $100 \%$ and $100 \%$, respectively, after 16 weeks with RBV. ${ }^{24}$ Treatmentemergent NS5A substitutions were observed at amino-acid positions M28A/G/T, Q30H/K/R/Y, L31F/M/V, H58D, and Y93H/N/S in HCV Gt 1a, L28M, L31F/V, and Y93H in HCV Gt 1b, and L28S/T, M31I/V, P58D and Y93H in HCV Gt 4. Treatment-emergent NS3 substitutions were also observed at amino-acid positions V36L/M, Y56H, V107I, R155I/K, $\mathrm{A} 156 \mathrm{G} / \mathrm{T} / \mathrm{V}, \mathrm{V} 158 \mathrm{~A}$, and D168A/G/N/V/Y in $\mathrm{HCV} \mathrm{Gt}$ 1a, Y56F, V107I and A156T in HCV Gt 1b, and A156M/T/V, D168A/G, and V170I in HCV Gt 4 among patients receiving EBR/GZR with and without RBV and who experienced virologic failure in Phase II or III clinical trials. ${ }^{19}$ The safety of EBR/GZR has been based on Phase II and III clinical studies, and the most commonly reported AEs are fatigue and headache. Rare cases $(0.8 \%)$ of substantial elevations in alanine aminotransferase levels have been reported. Less than $1 \%$ of subjects treated with EBR/GZR with or without RBV discontinued treatment due to AEs. 
Table 5 Efficacy and safety of elbasvir/grazoprevir (EBR/GZR) \pm ribavirin (RBV) in key clinical trials

\begin{tabular}{|c|c|c|c|c|c|c|c|c|c|}
\hline Clinical trial & Population & Regimen & $\begin{array}{l}\text { Duration } \\
\text { (weeks) }\end{array}$ & Gt & $\begin{array}{l}\text { Overall } \\
\text { SVR (\%) }\end{array}$ & $\begin{array}{l}\text { Gt Ia } \\
\text { SVR (\%) }\end{array}$ & $\begin{array}{l}\text { Gt Ib } \\
\text { SVR (\%) }\end{array}$ & $\begin{array}{l}\text { Gt } 4 \\
\text { SVR (\%) }\end{array}$ & $\begin{array}{l}\text { Severe } \\
\text { AEs (\%) }\end{array}$ \\
\hline C-SURFER ${ }^{30}$ & Advanced CKD & EBR/GZR & 12 & I & 94 & 97 & 92 & - & 15.6 \\
\hline C-EDGE TN ${ }^{17}$ & $\mathrm{TN} \pm$ cirrhosis & EBR/GZR & 12 & I, 4, 6 & 95 & 92 & 99 & 100 & 3.0 \\
\hline C-EDGE COINFECTION ${ }^{18}$ & $\mathrm{HIV}, \mathrm{TN} \pm$ cirrhosis & EBR/GZR & 12 & I, 4,6 & 96 & 97 & 96 & 96 & 0.9 \\
\hline C-EDGE TE ${ }^{24}$ & $\mathrm{P} / \mathrm{R} \pm$ cirrhosis $\pm \mathrm{HIV}$ & $\mathrm{EBR} / \mathrm{GZR} \pm \mathrm{RBV}$ & 12 or 16 & I, 4, 6 & 95 & 95 & 99 & 89 & 3.3 \\
\hline C-WORTHY33 & $\pm \mathrm{HIV}$ & $E B R / G Z R \pm R B V$ & 8 or 12 & 1 & 97 & 94 & 93 & - & 1.4 \\
\hline C-SALVAGE ${ }^{22}$ & $\mathrm{PI}+\mathrm{P} / \mathrm{R} \pm$ cirrhosis & $E B R / G Z R+R B V$ & 12 & I & 96 & 93 & 98 & - & 5.1 \\
\hline Japanese $\mathrm{e}^{20}$ & No cirrhosis & EBR/GZR & 12 & I & 97 & 100 & 96 & - & 0 \\
\hline
\end{tabular}

Abbreviations: AEs, adverse events; CKD, chronic kidney disease; Gt, genotype; PI, protease inhibitor; P/R, PEGylated interferon and ribavirin; SVR, sustained virological response; $\mathrm{TE}$, treatment-experienced; $\mathrm{TN}$, treatment-naïve.

\section{Advanced CKD}

The prevalence of HCV in patients with CKD is higher than that in the general population, with an incidence of $5 \%-10 \%$ in Europe and the USA. ${ }^{25,26}$ The prevalence of $\mathrm{HCV}$ is also closely associated with the length of time on hemodialysis. ${ }^{27}$ Moreover, dialysis patients with HCV have a higher mortality rate than those without HCV. ${ }^{28}$ In the long term, the treatment of $\mathrm{HCV}$-infected patients with CKD is limited by low efficacy and high AEs with IFN and RBV treatment. ${ }^{29}$ The development of DAAs has dramatically changed the prognosis for patients with HCV receiving dialysis. Until recently, all clinical trials excluded patients with CKD stage 4-5, due to a lack of safety data in patients with advanced CKD. However, this situation changed with the contribution of the C-SURFER study, ${ }^{30}$ which was the first randomized trial to include patients with CKD stage 4 to evaluate the efficacy and safety of EBR/GZR for HCV treatment. ${ }^{30}$ In this trial, 224 patients, $76 \%$ of whom were hemodialysis patients, were enrolled. This study included equal proportions of patients infected with HCV Gt 1a and $1 b$. SVR12 was achieved in $94 \%$ of patients. Six patients discontinued treatment for reasons other than virologic failure, and one noncirrhotic patient with HCV Gt $1 \mathrm{~b}$ and NS5A-L31M RASs experienced a virological relapse. AEs were observed in $15.6 \%$ of patients and were generally mild. The most frequent AEs were headache, nausea, and fatigue. Serious AEs did not lead to drug discontinuation. There was no significant renal or hepatic impairment. The well-tolerated oral regimens for HCV have expanded the treatment strategies available for patients with CKD stage $4-5$ and hemodialysis.

\section{HIV coinfection}

The overall global prevalence of HIV-HCV coinfection is about $6.2 \% .^{31} \mathrm{HIV}$ accelerates liver fibrosis in patients coinfected with HCV through several different mechanisms, ${ }^{32}$ and treatment for chronic $\mathrm{HCV}$ infection is urgently needed in this patient population. Sulkowski et $\mathrm{al}^{33}$ reported Phase II results of the C-WORTHY trial, which evaluated the efficacy of 8 or 12 weeks of EBR/GZR with or without RBV in HCV Gt 1 monoinfected and HIV-HCV coinfected patients. Rockstroh et a ${ }^{18}$ also reported Phase III results of the C-EDGE COINFECTION trial, which tested the efficacy of 12 weeks of EBR/GZR without RBV in patients with HIV and HCV Gt 1, 4, or 6 coinfection. This EBR/GZR regimen can be used in combination with HIV-integrase inhibitors and a number of nucleoside reverse-transcriptase inhibitors without any dosage adjustment. Both clinical trials showed high SVR rates and a good safety profile for EBR/GZR regimens.

\section{Compensated cirrhosis}

Rockstroh et $\mathrm{al}^{18}$ reported the effects of EBR/GZR in patients with $\mathrm{HCV}$ infection and compensated cirrhosis, combining data from six clinical trials (C-SURFER, ${ }^{30}$ C-EDGE COINFECTION, C-EDGE TN, ${ }^{17}$ and C-EDGE $\mathrm{TE}^{24}$ [Phase III], and C-WORTHY ${ }^{33}$ and C-SALVAGE ${ }^{22}$ [Phase II]). The authors performed integrated analysis of 402 patients with HCV genotype 1, 4, or 6 infection and Child-Pugh A compensated cirrhosis enrolled in six clinical trials. All patients received EBR/GZR with or without RBV for 12-18 weeks. Among TN and TE patients receiving EBR/GZR for 12 weeks, $97.8 \%$ and $88.9 \%$ achieved SVR12, respectively. Among patients receiving EBR/GZR for 12 weeks with RBV, the SVR12 rate did not increase in TN or TE patients. TE patients receiving EBR/GZR with or without RBV for 16 or 18 weeks achieved SVR12 of $100 \%$ and $93.9 \%$, respectively. Virologic failure was observed more frequently in Gt 1a-infected patients than in patients infected with Gt $1 \mathrm{~b}$ or 4 . HCV Gt 1a-infected patients with baseline RASs in NS5A receiving EBR/GZR for 12 weeks achieved SVR 12 of $73 \%$. Serious AEs were reported in 3\% of patients, and no patient had a hepatic failure-related event. 
Table 6 Treatment recommendations with elbasvir-grazoprevir (EBR/GZR) for HCV genotypes I and 4

\begin{tabular}{|c|c|c|c|}
\hline Guideline & Patients & Regimen & $\begin{array}{l}\text { Duration } \\
\text { (weeks) }\end{array}$ \\
\hline \multirow[t]{6}{*}{ AASLD/IDSA } & Gt la: TN or TE (P/R), without NS5A RASs & $\mathrm{EBR} / \mathrm{GZR}$ & 12 \\
\hline & Gt la: TN or TE (P/R), with NS5A RASs & $\mathrm{EBR} / \mathrm{GZR}+\mathrm{RBV}$ & 16 \\
\hline & Gt Ib: TN or TE (P/R) & $\mathrm{EBR} / \mathrm{GZR}$ & 12 \\
\hline & Gt la or Ib: TE (P/R/PI) & $\mathrm{EBR} / \mathrm{GZR}+\mathrm{RBV}$ & 12 \\
\hline & Gt 4: TN & $\mathrm{EBR} / \mathrm{GZR}$ & 12 \\
\hline & Gt 4: TE $(P / R)$ & $\mathrm{EBR} / \mathrm{GZR}+\mathrm{RBV}$ & 16 \\
\hline \multirow[t]{10}{*}{ EASL } & Gt la: TN or TE (P/R), no NS5A resistance testing, low HCV RNA & $\mathrm{EBR} / \mathrm{GZR}$ & 12 \\
\hline & Gt la: TN or TE (P/R), no NS5A resistance testing, high HCV RNA & $\mathrm{EBR} / \mathrm{GZR}+\mathrm{RBV}$ & 16 \\
\hline & Gt la: TN or TE (P/R), without NS5A RASs, low HCV RNA & $\mathrm{EBR} / \mathrm{GZR}$ & 12 \\
\hline & Gt la: TN or TE (P/R), without NS5A RASs, high HCV RNA ${ }^{b}$ & $\mathrm{EBR} / \mathrm{GZR}$ & 12 \\
\hline & Gt la: TN or TE, with NS5A RASs, low HCV RNAa & EBR/GZR & 12 \\
\hline & Gt la: TN or TE (P/R), with NS5A RASs, high HCV RNA ${ }^{b}$ & $\mathrm{EBR} / \mathrm{GZR}+\mathrm{RBV}$ or alternative treatment & 16 \\
\hline & Gt Ib: TN or TE $(P / R)$ & $\mathrm{EBR} / \mathrm{GZR}$ & 12 \\
\hline & Gt 4: TN & $\mathrm{EBR} / \mathrm{GZR}$ & 12 \\
\hline & Gt 4: TE (P/R), low HCV RNA ${ }^{a}$ & EBR/GZR & 12 \\
\hline & Gt 4: TE (P/R), high HCV RNA & $E B R / G Z R+R B V$ & 16 \\
\hline
\end{tabular}

Notes: aLow HCV RNA defined as $\leq 800,000$ (5.9 log) IU $/ \mathrm{mL}$; bhigh HCV RNA defined as $>800,000(5.9 \mathrm{log}) \mathrm{IU} / \mathrm{mL}$.

Abbreviations: AASLD, American Association for the Study of Liver Disease; EASL, European Association for the Study of the Liver; Gt, genotype; HCV, hepatitis C virus; IDSA, Infectious Diseases Society of America; PI, protease inhibitor; P/R, PEGylated interferon and ribavirin; RASs, resistance-associated substitutions; RBV, ribavirin; TE, treatment-experienced; TN, treatment-naïve.

\section{Decompensated cirrhosis}

Pharmacokinetic data from hepatic-impairment studies in non-HCV-infected subjects have demonstrated a decrease in EBR area under the curve in Child-Pugh A (39\%), ChildPugh B (28\%), and Child-Pugh C (12\%). ${ }^{34}$ In contrast, GZR exposure is increased in Child-Pugh A (double), Child-Pugh B (fivefold), and Child-Pugh C (12-fold) ${ }^{35}$ EBR/GZR use is contraindicated in patients with moderate (Child-Pugh B) or severe (Child-Pugh C) liver cirrhosis, as they may have significantly increased GZR exposure that might lead to an increased risk of elevated transaminase levels.

\section{Pangenotypic use}

The Phase II C-SCAPE study evaluated EBR/GZR with or without RBV in participants with HCV genotype 2, 4, 5, or 6 infection. ${ }^{36}$ Among participants with Gt 2 infection, SVR12 was achieved by $80 \%$ (24 of 30) of those receiving EBR/ GZR + RBV. The addition of RBV to EBR/GZR appeared to increase SVR 12 rates in participants with Gt 5 infection from $25 \%$ (one of four) to $100 \%$ (four of four). These results indicated that $\mathrm{EBR} / \mathrm{GZR} \pm \mathrm{RBV}$ was unsatisfactory in patients with HCV Gt 2 or 5 infection. SVR12 rates for HCV Gt 4 and 6 were similar to those found in other studies.

\section{Conclusion}

The ultimate goal of HCV therapy is not only to eradicate HCV infection but also to prevent HCV-related deaths, including liver-related disease, HCC, and extrahepatic complications. Current recommendations from the American Association for the
Study of Liver Disease, European Association for the Study of the Liver, and Infectious Diseases Society of America guidelines on EBR/GZR are shown in Table 6. Limitations of EBR/ GZR are the occurrence of potential concomitant drug-drug interactions, the absence of pangenotypic efficacy, the need for baseline evaluation of RASs in Gt 1a-infected patients, and the putative hepatotoxicity of protease inhibitors in Child-Pugh B and $\mathrm{C}$ cirrhosis in a minority of clinical situations. However, the fixed-dose once-daily oral combination regimen of EBR/ GZR has beneficial effects in antiviral treatment for HCV Gt 1- and 4-infected TN and TE patients, with or without compensated cirrhosis, HIV coinfection, or advanced CKD.

\section{Abbreviations}

AASLD, American Association for the Study of Liver Disease; $\mathrm{AE}$, adverse event; $\mathrm{CKD}$, chronic kidney disease; DAA, directacting antiviral; EASL, European Association for the Study of the Liver; EBR, elbasvir; Gt, genotype; GZR, grazoprevir; HCC, hepatocellular carcinoma; HCV, hepatitis C virus; IDSA, Infectious Diseases Society of America; LC, liver cirrhosis; NS, nonstructural; RAS, resistance-associated substitution; RBV, ribavirin; SVR12, sustained virological response at 12 weeks; TE, treatment-experienced; TN, treatment-naïve.

\section{Acknowledgments}

The authors gratefully acknowledge Koji Ogawa, Goki Suda, Takuya Sho, Masato Nakai, Takaaki Izumi, Machiko Umemura, Naoki Kawagishi, Masatsugu Ohara, and Kazuharu Suzuki from the Hepatology Department of 
Hokkaido University Hospital for helpful discussions. This review was not supported by external funding.

\section{Author contributions}

$\mathrm{KM}, \mathrm{AN}$, and TS cowrote the manuscript. KM and NS discussed and edited the paper. NS supervised the writing of the manuscript. All authors contributed toward data analysis, drafting and revising the paper and agree to be accountable for all aspects of the work.

\section{Disclosure}

NS has received lecture fees from Bristol-Myers Squibb and Janssen Pharmaceutical, grants and endowments from MSD and Chugai Pharmaceutical, and a research grant from Gilead Sciences. KM has received research grants from Gilead Sciences, Bristol-Myers Squibb, Otsuka Pharmaceutical, and Takeda Pharmaceutical. The authors report no other conflicts of interest in this work.

\section{References}

1. Alkhouri N, Lawitz E, Poordad F. Novel treatments for chronic hepatitis C: closing the remaining gaps. Curr Opin Pharmacol. 2017;37: 107-111.

2. Bukh J. The history of hepatitis $\mathrm{C}$ virus (HCV): basic research reveals unique features in phylogeny, evolution and the viral life cycle with new perspectives for epidemic control. J Hepatol. 2016;65(1 Suppl):S2-S21.

3. World Health Organization. Global Hepatitis Report. Geneva: WHO; 2017.

4. Petruzziello A, Marigliano S, Loquercio G, Cozzolino A, Cacciapuoti C. Global epidemiology of hepatitis $\mathrm{C}$ virus infection: an up-date of the distribution and circulation of hepatitis $\mathrm{C}$ virus genotypes. World $J$ Gastroenterol. 2016;22(34):7824-7840.

5. Coburn CA, Meinke PT, Chang W, et al. Discovery of MK-8742: an HCV NS5A inhibitor with broad genotype activity. ChemMedChem. 2013;8(12):1930-1940.

6. Summa V, Ludmerer SW, Mccauley JA, et al. MK-5172, a selective inhibitor of hepatitis $\mathrm{C}$ virus NS3/4a protease with broad activity across genotypes and resistant variants. Antimicrob Agents Chemother. 2012;56(8): 4161-4167.

7. Macdonald A, Harris M. Hepatitis C virus NS5A: tales of a promiscuous protein. J Gen Virol. 2004;85(Pt 9):2485-2502.

8. Masaki T, Matsunaga S, Takahashi H, et al. Involvement of hepatitis $\mathrm{C}$ virus NS5A hyperphosphorylation mediated by casein kinase I- $\alpha$ in infectious virus production. J Virol. 2014;88(13):7541-7555.

9. McGivern DR, Masaki T, Williford S, et al. Kinetic analyses reveal potent and early blockade of hepatitis C virus assembly by NS5A inhibitors. Gastroenterology. 2014;147(2):453.e7-462.e7.

10. Ross-Thriepland D, Harris M. Hepatitis C virus NS5A: enigmatic but still promiscuous 10 years on! J Gen Virol. 2015;96(Pt 4):727-738.

11. Lahser FC, Bystol K, Curry S, et al. The combination of grazoprevir, a hepatitis $\mathrm{C}$ virus (HCV) NS3/4A protease inhibitor, and elbasvir, an HCV NS5A inhibitor, demonstrates a high genetic barrier to resistance in HCV genotype 1a replicons. Antimicrob Agents Chemother. 2016;60(5): 2954-2964.

12. Moradpour D, Penin F, Rice CM. Replication of hepatitis C virus. Nat Rev Microbiol. 2007;5(6):453-463.

13. Morikawa K, Gouttenoire J, Hernandez C, et al. Quantitative proteomics identifies the membrane-associated peroxidase GPx 8 as a cellular substrate of the hepatitis C virus NS3-4A protease. Hepatology. 2014;59(2):423-433.
14. Morikawa K, Lange CM, Gouttenoire J, et al. Nonstructural protein 3-4A: the Swiss army knife of hepatitis C virus. J Viral Hepat. 2011;18(5): 305-315.

15. Asante-Appiah E, Curry S, Mcmonagle P, et al. Antiviral activity and resistance analysis of NS3/4A protease inhibitor grazoprevir and NS5A inhibitor elbasvir in hepatitis C virus GT4 replicons. Antimicrob Agents Chemother. 2017;61(7):e00363-17.

16. Liu R, Curry S, Mcmonagle P, et al. Susceptibilities of genotype 1a, $1 \mathrm{~b}$, and 3 hepatitis $\mathrm{C}$ virus variants to the NS5A inhibitor elbasvir. Antimicrob Agents Chemother. 2015;59(11):6922-6929.

17. Zeuzem S, Ghalib R, Reddy KR, et al. Grazoprevir-elbasvir combination therapy for treatment-naive cirrhotic and noncirrhotic patients with chronic hepatitis $\mathrm{C}$ virus genotype 1, 4, or 6 infection: a randomized trial. Ann Intern Med. 2015;163(1):1-13.

18. Rockstroh JK, Nelson M, Katlama C, et al. Efficacy and safety of grazoprevir (MK-5172) and elbasvir (MK-8742) in patients with hepatitis $\mathrm{C}$ virus and HIV co-infection (C-EDGE CO-INFECTION): a non-randomised, open-label trial. Lancet HIV. 2015;2(8):e319-e327.

19. Komatsu TE, Boyd S, Sherwat A, et al. Regulatory analysis of effects of hepatitis C virus NS5A polymorphisms on efficacy of elbasvir and grazoprevir. Gastroenterology. 2017;152(3):586-597.

20. Kumada H, Suzuki Y, Karino Y, et al. The combination of elbasvir and grazoprevir for the treatment of chronic HCV infection in Japanese patients: a randomized phase II/III study. J Gastroenterol. 2017;52(4): $520-533$.

21. Dore GJ, Altice F, Litwin AH, et al. Elbasvir-grazoprevir to treat hepatitis $\mathrm{C}$ virus infection in persons receiving opioid agonist therapy: a randomized trial. Ann Intern Med. 2016;165(9):625-634.

22. Forns X, Gordon SC, Zuckerman E, et al. Grazoprevir and elbasvir plus ribavirin for chronic $\mathrm{HCV}$ genotype-1 infection after failure of combination therapy containing a direct-acting antiviral agent. $J$ Hepatol. 2015;63(3):564-572.

23. Hézode C, Colombo M, Bourlière $\mathrm{M}$, et al. Elbasvir/grazoprevir for patients with hepatitis $\mathrm{C}$ virus infection and inherited blood disorders: a phase III study. Hepatology. 2017;66(3):736-745.

24. Kwo P, Gane EJ, Peng CY, et al. Effectiveness of elbasvir and grazoprevir combination, with or without ribavirin, for treatment-experienced patients with chronic hepatitis C infection. Gastroenterology. 2017; 152(1):164.e4-175.e4.

25. Baid-Agrawal S, Pascual M, Moradpour D, Frei U, Tolkoff-Rubin N. Hepatitis $\mathrm{C}$ virus infection in haemodialysis and kidney transplant patients. Rev Med Virol. 2008;18(2):97-115.

26. Marinaki S, Boletis JN, Sakellariou S, Delladetsima IK. Hepatitis C in hemodialysis patients. World J Hepatol. 2015;7(3):548-558.

27. Fabrizi F. Hepatitis $\mathrm{C}$ virus infection and dialysis: 2012 update. ISRN Nephrol. 2013;2013:159760.

28. Carbone M, Mutimer D, Neuberger J. Hepatitis C virus and nonliver solid organ transplantation. Transplantation. 2013;95(6):779-786.

29. McHutchison JG, Lawitz EJ, Shiffman ML, et al. PEGinterferon alfa-2b or alfa-2a with ribavirin for treatment of hepatitis $\mathrm{C}$ infection. $N$ Engl J Med. 2009;361(6):580-593.

30. Roth D, Nelson DR, Bruchfeld A, et al. Grazoprevir plus elbasvir in treatment-naive and treatment-experienced patients with hepatitis $\mathrm{C}$ virus genotype 1 infection and stage 4-5 chronic kidney disease (the C-SURFER study): a combination phase 3 study. Lancet. 2015;386(10003): $1537-1545$.

31. Platt L, Easterbrook P, Gower E, et al. Prevalence and burden of HCV co-infection in people living with HIV: a global systematic review and meta-analysis. Lancet Infect Dis. 2016;16(7):797-808.

32. Chen JY, Feeney ER, Chung RT. HCV and HIV co-infection: mechanisms and management. Nat Rev Gastroenterol Hepatol. 2014;11(6): 362-371.

33. Sulkowski M, Hezode C, Gerstoft J, et al. Efficacy and safety of 8 weeks versus 12 weeks of treatment with grazoprevir (MK-5172) and elbasvir (MK-8742) with or without ribavirin in patients with hepatitis $\mathrm{C}$ virus genotype 1 mono-infection and HIV/hepatitis $\mathrm{C}$ virus co-infection (C-WORTHY): a randomised, open-label phase 2 trial. Lancet. 2015;385(9973):1087-1097. 
34. Marshall WL, Feng HP, Wenning L, et al. Pharmacokinetics, safety, and tolerability of single-dose elbasvir in participants with hepatic impairment. Eur J Drug Metab Pharmacokinet. 2018;43(3):321-329.

35. Caro L, Wenning L, Guo Z, et al. Effect of hepatic impairment on the pharmacokinetics of grazoprevir, a hepatitis $\mathrm{C}$ virus protease inhibitor. Antimicrob Agents Chemother. 2017;61(12):e00813-17.
36. Brown A, Hézode C, Zuckerman E, et al. Efficacy and safety of 12 weeks of elbasvir \pm grazoprevir \pm ribavirin in participants with HCV genotype 2, 4, 5, or 6 infection: the C-SCAPE study. J Viral Hepat. 2018; $25(5): 457-464$.

\section{Publish your work in this journal}

Drug Design, Development and Therapy is an international, peerreviewed open-access journal that spans the spectrum of drug design and development through to clinical applications. Clinical outcomes, patient safety, and programs for the development and effective, safe, and sustained use of medicines are the features of the journal, which has also been accepted for indexing on PubMed Central. The manuscript management system is completely online and includes a very quick and fair peer-review system, which is all easy to use. Visit http://www.dovepress.com/testimonials.php to read real quotes from published authors.

Submit your manuscript here: http://www.dovepress.com/drug-design-development-and-therapy-journal 